\title{
Large scale implementation of Solar Home Systems in remote, rural areas
}

\author{
Hans-Peter Bader, Markus Real, Ruth Scheidegger
}

Abstract Large-scale implementation of Solar Home Systems (SHSs) to provide electricity for people lacking electric power may have several constraints. Some of these are on the input side to realise the potential, and some are on the dismantling side, which are concerned with environmental issues. The questions analysed within this study are: will the industrial production capacity and distributor network grow fast enough to serve market demand and does the flux of lead induced by such a global growth of SHS represent a potential hazard to the environment. Some of the surprising findings are as follows. (i) The photovoltaic (PV) module and other SHS components can be manufactured on time to serve the growing market, even if implementation will take place over 25 years.

(ii) The setting up of a distribution network represents a real bottleneck. (iii) Enhancing the average lifetime of SHS batteries from 3 to 5 years, which will result from an improved quality procedure such as implemented by the PV Global Approval Process (PVGAP), has the same effect as improving the recycling rate by $40 \%$ and is therefore undoubtedly the most appropriate urgent first step in reducing the impact of lead from SHS on the environment. In addition, recycling rates should be enhanced, and financial agencies and PV distributors may play an important role in stimulating the installation of facilities to undertake the proper recycling of used batteries.

\section{Introduction}

It is estimated that worldwide about 2 billion people are living without electricity (Global Green 2001). Grid-independent photovoltaic (PV) systems offer a cost effective option to provide those people with electrical services. Today, most applicable systems comprise PV module(s), battery, charge controller and the loads, mainly lights, but

Received: 12 March 2003 / Accepted: 20 March 2003

Published online: 29 May 2003

(C) Springer-Verlag 2003

H.-P. Bader ( $)$, R. Scheidegger

EAWAG, Überlandstr. 133, 8600 Dübendorf, Switzerland

E-mail: bader@eawag.ch

Tel.: +41-1-8235501

Fax: +41-1-8235226

M. Real

Alpha Real AG, Feldeggstr. 89, 8008 Zürich, Switzerland

We thank an anonymous referee for some very helpful suggestions. also TV, radio, refrigerators and water pumps. Often referred to as Solar Home Systems (SHSs), they are designed in such a way that each home has one set of a system to itself, and typically have a PV power of $50 \mathrm{~W}$ and a storage capacity of $100 \mathrm{~A}$ h corresponding to a large car battery (Lambert 2001). Two questions that immediately arise are:

(i) Are solar home systems a realistic option to provide electricity for these people?

(ii) How sustainable would this option be with reference to the impacts on the environment?

To answer these key questions, the following assumptions are made:

1. About half of the people with no electricity today will get electricity from PV SHSs rather than from grid extensions. This amounts to roughly 1 billion people, or 200 million households, which then corresponds to 200 million SHSs. In this number, for ease of calculation, it is also assumed that the increase in global population will either not have electricity or receive their power from grid extensions. It is further assumed that such an anticipated large-scale implementation will follow a sigmoidal growth curve.

2. The nominal PV power of each SHS is assumed to be on the average $50 \mathrm{~W}$, which corresponds to a yearly accumulated electrical service in the order of $100 \mathrm{~kW} \mathrm{~h}$. For comparison, the average industrial household has a yearly electrical consumption in the range from 4,000 to $8,000 \mathrm{~kW} \mathrm{~h}$. Considering energy saving technologies, this consumption may drop to $2,000 \mathrm{~kW}$ h, which still is 20 times higher than what will be provided by SHSs to rural populations in developing countries. It is assumed that the average power of an individual SHS will increase linearly over the next 30 years from 50 to $300 \mathrm{~W}$, due to an increase in wealth, better established financial structure and lower PV system costs. This will bring the level of yearly energy usage to about $600 \mathrm{~kW} \mathrm{~h}$, which compares well with the $2,000 \mathrm{~kW}$ h on an optimised industrial standard. However, batteries will only double in storage capacity from $80 \mathrm{~A} h$ to $160 \mathrm{~A} \mathrm{~h}$, because many of the additional loads will be used during daytime, such as water pumping, air conditioning or refrigeration. Such additional loads require no expansion of storage capacity in contrast to additional loads used during night time.

3. It is also assumed that, further along the learning curve, some of the market for individual PV SHSs will be replaced by PV minigrids. Though the total amount of 
installed PV power will remain the same, independent of technical solutions, it is assumed that this will also be the case for the battery storage (although in larger minigrids, hybrid systems may reduce storage capacity). These alterations have only a minor impact on the overall results and conclusions of the analysis and are neglected.

Within this set of assumptions, the two key questions can be formulated more precisely:

(i) How large is the required global industrial manufacturing capacity of PV modules to meet this demand, and how does the production need evolve over time? How will the required manufacturing rate be influenced by the assumption that in the future SHSs will have a $300-\mathrm{W}$ rather than the typical $50-\mathrm{W}$ power level of today? The manufacturing capacity will need to include the replacement of those PV modules that have reached the end of their operational lifetime. The lifetime of an SHS is assumed to be 20 years. A Gaussian distribution for the lifetime is assumed, representing the fact that some systems will last longer and others may fail before reaching 20 years of lifetime.

(ii) Concerning environmental aspects, lead (in batteries) is the most critical element used in SHS technology. Lead acid batteries are assumed to remain the main option for SHS energy storage due to their relatively low price compared to other options. Batteries, however, are known to require more frequent replacement, and an average lifetime of 3 years has been assumed. Since each SHS battery has an inventory of an average of $22 \mathrm{~kg}$, initial installation and the required periodic replacement induce a high flux of lead. The questions dealt with in this study are threefold: how does this flux evolve over time, how does it compare with the known flux of lead needed for automotive applications and what will be the remaining flux to the environment, assuming that $100 \%$ recycling is not feasible.

(iii) Two major parameters may influence such a flux to the environment: first improving the lifetime by using better SHSs and secondly improving the recycling rate from an assumed $10 \%$ today to $50 \%$ or even $90 \%$. The first parameter is mainly influenced by improvements in SHS and component quality, as may be attained by applying a recognised quality system such as the PV Global Approval System (PV GAP). The battery recycling parameter is of a logistic nature, and may be influenced by manufacturers, distributors and especially by financial institutions which are providing funds for the large scale implementation:

- Parameter I: battery lifetime. Increasing the battery lifetime from today's average of 3 years to 5 years in the future is assumed, by improving quality management both in the manufacturing of the batteries and in the system design and installations, including user training, as being implemented by international organisations such as PV GAP.
- Parameter II: recycling rate. Improving battery recycling by various economical and organisational means from rates as low as $10 \%$ today to $50 \%$ or $90 \%$ in the future, as may be implemented by national organisations or international financial support organisations.

In order to answer these questions, a dynamic model, based on material flow analysis, is applied, which was developed at the Swiss Federal Institute of Technology, Zurich. The method and the model will be explained briefly. Specific aspects of lead are discussed on the basis of a case analysis, taking Brazil as the model country. This study is related to a previous work with the subject "Large scale introduction of renewable energy systems in Switzerland" (Real 1998).

\section{Method}

The method applied in this study is "material flow analysis". This method has been described in detail in the literature (Baccini and Bader 1996). It has been successfully applied in numerous case studies (Zeltner et al. 1999; Real 1998; Müller 1998; Binder et al. 2001; Hug 2002) and ongoing work. Here only the most important steps are briefly explained. The first step is the system analysis, the second the mathematical description, the third the calibration and the fourth the simulation including sensitivity analysis and uncertainty analysis.

\section{System analysis}

The system analysis defines the system border and all the processes (boxes) and interactions (arrows) in between and with the "environment" taken into account. Clearly, the system depends very much on the questions to be answered. With regard to the questions to be investigated in this analysis, the following main indicators have been chosen: (i) the number of installed PV modules, (ii) the number of new installations per year, (iii) the chemical element lead.

Lead is an important indicator since this element is generally used in car and SHS batteries because of its low price and its availability. In fact, the choice of SHS battery storage depends and will continue to depend on the automotive industry, where they are used in large quantities. Although other, and technically better, options for storing electrical energy are available (or being tested in laboratories), no other viable option is conceivable at the present moment. In terms of environmental consideration as well as availability and performance of SHS, the lead acid battery is not the optimal choice, but no serious competitor is in sight. Therefore, within this study it is assumed that the lead acid battery will remain the main storage option and the questions then are:

- How large is the actual and accumulated induced flux of lead to the environment resulting from the planned large-scale introduction of SHSs?

- How large or significant is it compared with the corresponding flux of the automotive industry?

Car batteries are different from those in SHSs. Car batteries need good starting capacities, which require high

\section{9}




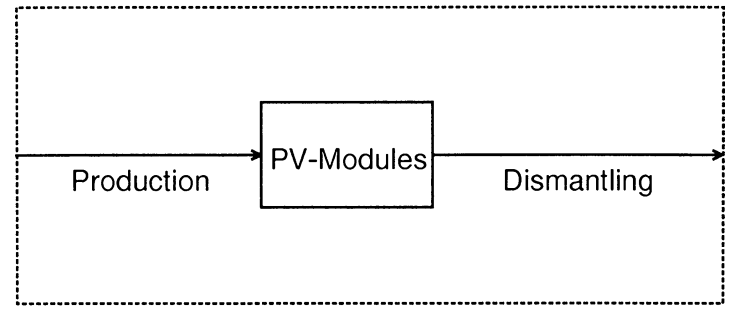

Fig. 1. System analysis for PV module production and dismantling

current capacities. SHS batteries, however, need to have high cycling capacities combined with a high amount of storage. This is achieved by making their lead plates thicker, which adds considerably more lead to SHS batteries.

For the analysis, two independent systems are established, as shown in Fig. 1 and Fig. 2 respectively. The first system is the "PV module system": the process PV module describes the capacity of PV modules implemented worldwide. The production and dismantling capacity per year are described by the input "production" and the output "dismantling".

The second system is the induced "lead flux system" exemplified by Brazil: processes 1 to 5 describe the lead stored in ores, car batteries and SHS batteries and the lead already deposited in landfills. The interactions between these represent the lead flux induced by the production of car and SHS batteries. Brazil instead of the whole world has been chosen for two reasons. First, Brazil has a high potential for SHSs in rural areas and second, the data availability for car batteries (to compare with SHS batteries) is high.

These two systems are tailor made to study the two key questions mentioned above. Of course they are in principle subsystems of the overall "PV world system", consisting of all processes to produce, maintain, operate and dismantle PV modules worldwide.

\section{Mathematical model}

Here the procedure is described for the "PV module system" of Fig. 1. (for the "lead flux system" of Fig. 2 see Appendix). The system of Fig. 1 is mathematically described by the following variables:
$I(t)$ : accumulated installed PV modules at time $t$

$O(t)$ : number of produced PV modules per year

$E(t)$ : number of dismantled PV modules per year

$M(t)$ : accumulated installed power at time $t$

The system equations describing the system behaviour for given initial conditions consist of a balance equation and the so-called model equations.

Balance equation:

$\dot{M}(t)=I(t)-O(t)$

where $\dot{M}(t)$ is the derivative of $M(t)$ with respect to time Model equations:

(a) Assumed implementation: $P_{1}(t)$

$M(t)=P_{1}(t)$

where $P_{1}(t)$ is a parameter function describing the assumed implementation of SHS as a function of time.

(b) Assumed residence time distribution $k\left(t, t^{\prime}\right)$

$O(t)=\int_{0}^{t} k\left(t, t^{\prime}\right) I\left(t^{\prime}\right) \mathrm{d} t^{\prime}$

where $k\left(t, t^{\prime}\right)$ is the transfer function or residence time distribution of PV modules produced at time $t$ '.

(c) Accumulated installed power:

$E(t)=\int_{0}^{t} P_{2}\left(t^{\prime}\right) I_{\text {Rest }}\left(t, t^{\prime}\right) \mathrm{d} t^{\prime}$

where $P_{2}\left(t^{\prime}\right)$ represents the power of a PV module produced at time $t^{\prime} . I_{\text {Rest }}\left(t, t^{\prime}\right)$ is the number of PV modules produced at time $t^{\prime}$, which are still in operation at time $t$.

The three parameter functions $P_{1}(t), P_{2}(t)$ and $k\left(t, t^{\prime}\right)$ are the characteristic quantities determining the behaviour of the "PV module system" above. The specific power $P_{2}(t)$ and the residence time distribution $k\left(t, t^{\prime}\right)$ are "technical functions" representing the state of the art of PV module production at time $t^{\prime}$. The implementation the characteristic $P_{1}\left(t^{\prime}\right)$ on the other hand is defined by the various actors.

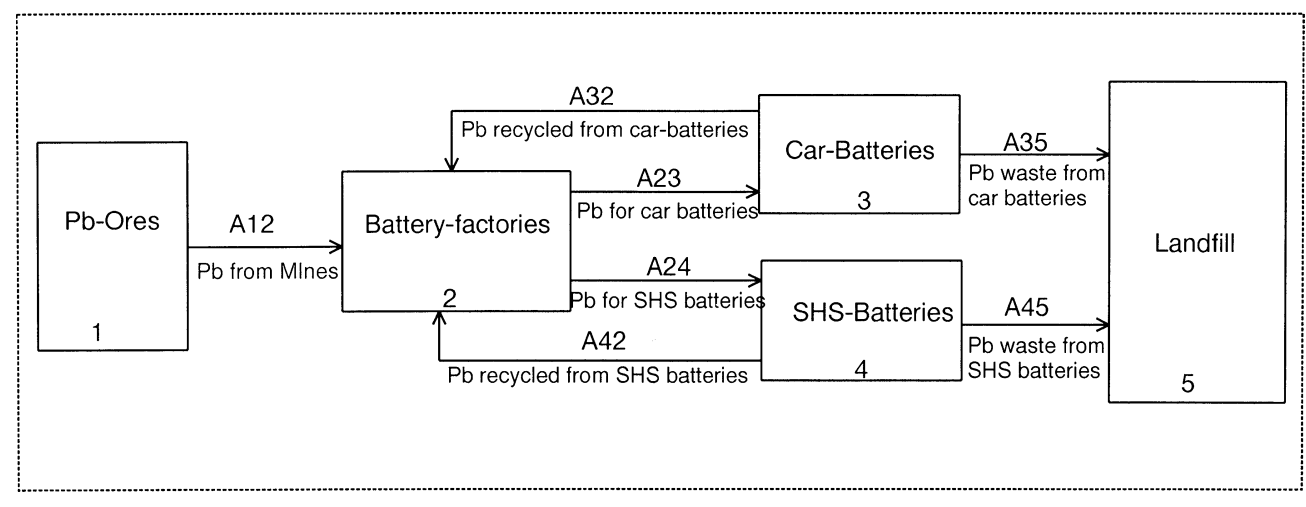

Fig. 2. System analysis for lead fluxes induced by PV module operation in Brazil 


\section{Calibration}

Calibration means finding the most suitable parameter functions to describe the available data. Of course this is in general not uniquely possible. However, the criteria that the parameter functions should be as simple as possible can help in choosing between several possibilities. In this sense, the following parameter and parameter functions for the two systems were found to be suitable.

\section{Implementation function $\boldsymbol{P}_{\mathbf{1}}(\boldsymbol{t})$}

Today, the total global installed capacity of PV modules amounts to almost $1 \mathrm{GW}$, of which only about $20 \%$ is used for stand-alone applications. This amount was about $80 \%$ in the past (1995). However, in the last 5 years the amount has decreased continuously and it is expected to reach about $20 \%$ in the near future (EU2 1996). Other applications power some 200,000 remote houses in rural areas, mainly in developing countries, but also in developed countries. (In Switzerland, for example, some 13,000 SHSs are in operation, to bring electricity to remote recreation homes, which are too remote to be reached from the national grid.) It is assumed that, within the next 25 to 50 years, this number will grow to 200 million SHSs, giving a basic electrical services to about one billion people, who would otherwise remain dependent on kerosene or candles for their lighting needs and have no access to radio, TV or other modern appliances. Figure 3 a shows the assumed growth, which is a typical curve of sigmoidal growth, as seen in nature and for industrial goods. The pattern is characterised by a slow introduction of the new technology, a steep growth in application in the middle and signs of market saturation towards the end, when the majority of a typical market consumer already has the new appliances.

The mathematical form of $P_{1}(t)$ is as follows:

$P_{1}(t)=p_{1,1}+\frac{p_{1,2}}{1+\mathrm{e}^{-p_{1,3}\left(t-p_{1,4}\right)}} \quad$ logistic growth

The parameters $p_{1,1}, \ldots, p_{1,4}$ follow from the starting and saturation values, the maximum growth rate and the turning point. They are listed in Table 1.

\section{Residence time distribution $k(t, t)$}

It is assumed that the average lifetime of the installed PV modules is 20 years for applications in tropical climates, compared to expected lifetimes of 25 to 30 years of PV modules installed in colder climates such as in Europe. That means that installed PV modules will be replaced by new ones after 20 years. Since not all modules will fail at the same time, a Gaussian distribution of lifetimes is assumed, with a standard deviation of 5 years. Figure $3 \mathrm{~b}$ shows the assumed distribution of lifetimes of PV modules in tropical climates, where most of the expected SHSs will be installed.

The mathematical form of $k\left(t, t^{\prime}\right)$ is:

$k\left(t, t^{\prime}\right)=\frac{1}{N_{0}} \mathrm{e}^{-\frac{\left(t-t^{\prime}-\tau\right)^{2}}{2 \sigma^{2}}} \quad$ PVmodulelifetimedistribution

where $N_{0}$ is a normalisation factor, $\tau$ is the average residence time and $\sigma$ is the standard deviation of $\tau$. For values of the parameters $\tau$ and $\sigma$ see Table 1 .

\section{Specific power $\boldsymbol{P}_{2}(t)$}

It is assumed that the power of SHSs may slowly and linearly increase over the next 30 years from $50 \mathrm{~W}$ to $300 \mathrm{~W}$ as a result of lower system costs, better financial structure and increased wealth among some parts of the rural population, see Fig. 3c.

A similar discussion applies to the six parameter functions of the "lead system" introduced in the Appendix, as follows.

The case analysis is exemplified by Brazil. Today, the population in Brazil amounts to 170 million people, and roughly $20 \%$ have no access to the electrical grid and are relying on kerosene and candles for their lighting needs and live in the hope for future grid extension. It is assumed that within the next 50 years 1.5 million households will require a PV SHS to power the basic needs of the part of the rural population which can not be reached by grid extensions, giving electricity to some 7.5 million Brazilians. The assumed power level is $50 \mathrm{~W}$ per SHS, with a battery of $80 \mathrm{~A} \mathrm{~h}$. The need for car batteries is derived from the fact that today some 15 million cars are registered in Brazil, and it is assumed 
Table 1. Values of the parameters for the various parameter functions

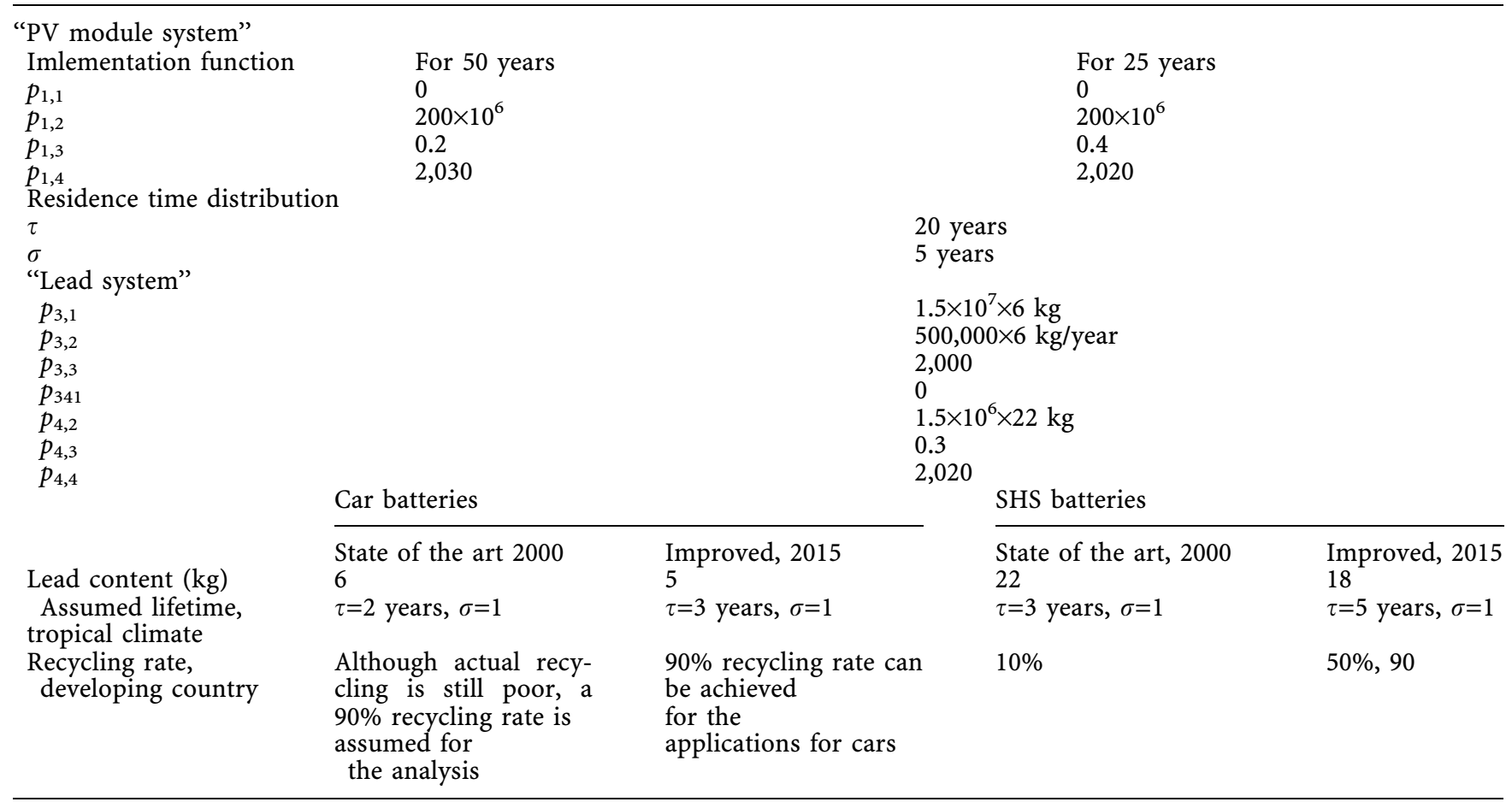

that this value will double in the next 50 years, growing linearly.

Today, very few countries have a recycling policy that is strict enough to include the cost for recycling in the selling price. Since lead is relatively cheap, recycling of lead does not repay the work of scratching the lead from batteries, and there is no financial incentive for returning used lead batteries to the recycling stream. In developing countries, some of the lead may be used for other purposes, before it finds its ultimate deposition somewhere in the ground.

Battery lifetime and recycling rates are key elements when trying to estimate the overall flux of the lead. This is true for applications in both the automotive and the PV SHS market segment. There are no statistical data available, but based on investigations by the authors the following assumptions seem to be fairly solid.

Car batteries, under tropical conditions, will last 2 years ${ }^{1}$, while the lifetime of batteries in SHSs depends on the quality management of the component manufactures, SHS component configuration and installers. Once again, there are no statistical data available, but based on statements for the PV industry an average lifetime of 3 years has been assumed. Again, not all the batteries will fail at the same time, and a Gaussian distribution curve has been assumed for assumed battery lifetimes. The

\footnotetext{
${ }^{1}$ There are no data available on this issue. The 2-year assumption is the result of personal inquiries by the authors of consumers, battery retailers and local car maintenance people. It seems that the elevated temperature in tropical climates as well as the poor quality of locally manufactured batteries may contribute to the fact that batteries in hot climates do not last as long as those in temperate climates in industrialised countries.
}

manufacturing process for lead acid batteries is far from being optimised, and improved quality control combined with technological progress will lead to improved battery lifetimes.

Recycling rates of lead acid batteries for both car and SHS applications are still very poor, except for some industrialised countries, which have demonstrated that recycling rates of almost $100 \%$ are feasible. In developing countries, recycling levels even for car batteries are still low, and are much lower for SHSs. The reason why car batteries are in general easier to recycle is that they-by their nature-are transported in the car, and no real physical effort is needed by the user to bring batteries back into the recycling stream. SHSs are, on the other hand, by their very nature far from the grid, which normally also implies distance from other infrastructure support. Very often, these sites are not even accessible by car, which makes it even more difficult to bring the batteries back for recycling.

Still, environmental pressure, requirements from financing institutions and higher lead prices will hopefully boost recycling rates.

The corresponding parameter values are also listed in Table 1.

Simulations on the basis of these parameter values have been done with the computer program SIMBOX.

\section{Results and discussion}

\section{"PV module system"}

The required production volume in number of SHSs and in $\mathrm{kW}$ per year as well as the accumulated installed power are calculated for the following three cases: 


\begin{tabular}{|c|c|c|}
\hline \multirow[t]{3}{*}{ (i) } & Base case & \\
\hline & Implementation time & 50 years (see Table 1 ) \\
\hline & Specific power & $50 \mathrm{~W} / \mathrm{SHS}$ \\
\hline \multirow[t]{3}{*}{ (ii) } & Scenario & \\
\hline & "rapid implementation" & \\
\hline & $\begin{array}{l}\text { Implementation time } \\
\text { Specific power }\end{array}$ & $\begin{array}{l}25 \text { years (see Table } 1) \\
50 \mathrm{~W} / \mathrm{SHS}\end{array}$ \\
\hline \multirow[t]{3}{*}{ (iii) } & $\begin{array}{l}\text { Scenario "improved } \\
\text { specific power" }\end{array}$ & 50 sivivis \\
\hline & Implementation time & 50 years (see Table 1 ) \\
\hline & Specific power & see Fig. 3c \\
\hline
\end{tabular}

Of course not all SHSs will have the same power level. In fact, many systems sold today have a power level as low as $20 \mathrm{~W}$, but others are over $50 \mathrm{~W}$. It is assumed that the distribution of power will also be Gaussian. For the residence lifetime distribution the parameters shown in Table 1 were used.

Figure 4 shows the results of the simulation. Of course the figure only shows the number of PV modules (in $\mathrm{kW}$ ), which is required to fulfil the need for the SHS market. Other PV market needs such as for grid connected telecommunication or consumer goods are not included. Clearly if the total global PV production is smaller than the SHS market need, competing market forces will apply which may even lower the speed of SHS market implementation.

It is important to note the peak in the production capacity, especially for fast implementation of SHS. This behaviour is typical for each introduction of a new product. The higher the peak, the larger the overcapacity in production, which was necessary for the "growth phase" but not for the "replacement phase". This phenomenon clearly limits the reduction of the implementation time. Nevertheless, a possibility for a faster growth of the installed power is given by the improvement of the specific power per SHS as clearly shown in Fig. 4 by the scenario "improved specific power".

\section{"Lead system"}

The goal of the simulation is to calculate and compare the induced fluxes of lead for both the car and the SHS industries.

It is assumed that today's poor recycling rate for car batteries will increase even for less developed countries to the high level of $90 \%$ recycling rate, only experienced today in some highly industrialised countries. The reasons for this optimistic assumption are: (i) lead price will rise and stimulate recycling by economic incentives and (ii) environmental issues and improved recycling infrastructure will be implemented also in less industrialised areas. Further, it is assumed that technological improvements in car batteries will enhance their lifetimes from today's 2 to 3 years in the envisaged time horizon (see Table 1). The growth functions for cars and PV systems in Brazil were chosen according to Table 1 . For SHSs this leads to a maximum production of $5 \mathrm{MW} /$ year in the year 2025. The question is how much lead will be introduced into the environment from SHSs, especially in comparison with the automotive industry.

Figure 5 shows the results for the flux to the environment. In particular, it can be seen how extending the PV lifetime and improving the recycling rate influence this flux.

At a recycling rate of $10 \%$ (base case), which unfortunately is most probably the situation today, the amount of lead will grow over time to an unacceptable value of 10,000 tons/year in the year 2050 (about twice as high as for cars).

An improved recycling rate of $90 \%$ can bring this value down to levels that can compare to the flux of lead from the automotive industry today. In Fig. 5, the effect of improving battery lifetime from 3 to 5 years is shown. At a first view it is surprising that this measure has about the same degree of reduction of flux of lead to the environment as improving the recycling rate by $40 \%$. However, an improvement of the recycling rate from $10 \%$ to $50 \%$ results in a reduction of the deposition rate from $90 \%$ to $50 \%$, which is about a factor of 2 . Clearly this has the same effect as doubling the residence time. Since improving battery lifetime is also an imperative economic goal, it is a measure that must be implemented. Existing SHSs demonstrate the technical feasibility of the measure. As it seems today, it is an issue of improved quality control, both in manufacturing the components and in the system design. Several international agencies have been concerned with this issue, such as PV GAP.

\section{Conclusions}

The result of the dynamic simulation of large-scale implementation of PV SHSs leads to the following significant conclusions:

1. Even if typical SHS power levels were to be ramped up from today's $50 \mathrm{~W}$ to a future $300 \mathrm{~W}$ per SHS, the total installed power would be limited to around $30 \mathrm{GW}$. This is of major significance for the quality of life of the rural population and for the PV business. The impact on mitigation of global climate change at a purely power level is still minor, but can only be estimated when all additional side effects are considered, such as that people with no access to electricity may be more likely to move into towns, where their contribution to greenhouse gases will grow for other reasons.

2. To serve such a worldwide market, in the year 2015 a distribution and installer network is required to implement around 20 million new SHSs per year. Considering the poor availability of qualified installers and the missing microfinance structure, this seems inconceivable, or at least it would require a major effort to achieve this goal.

3. Assuming that the automotive industry attains a $90 \%$ recycling rate, the flow of lead from the SHS market to the environment will grow fivefold if the recycling rate remains low-at 10\%-and average battery lifetime stays down at 3 years. On the other hand, the flux of lead will be about the same as that from the automotive industry if its recycling rate can be increased to a level of $50 \%$.

4. Improving quality control to increase the average SHS battery lifetime from 3 to 5 years results in a dramatic reduction of lead flow to the environment-of the same order as increasing the recycling rate from 10 to $50 \%$. 
Mio SHS Production Volume of SHS

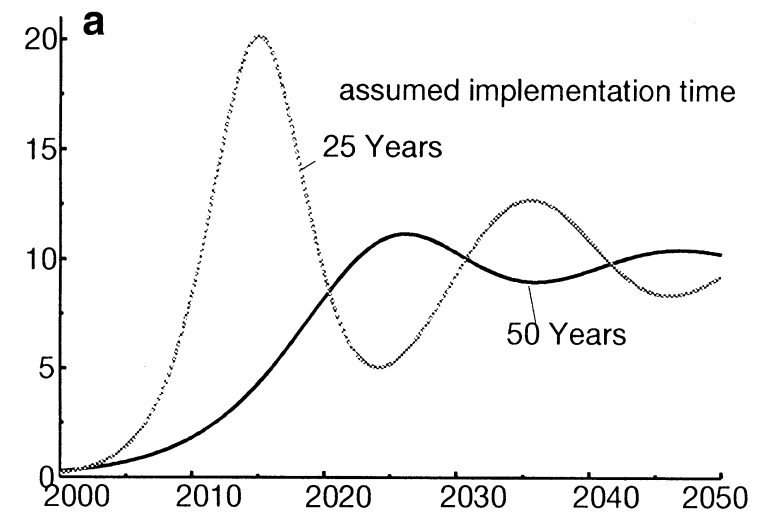

Fig. 4a-c. Simulation results for the "PV module" system. $\mathbf{a}$ and $\mathbf{b}$ The required production volume in number of SHS/year and $\mathrm{kW} /$ year respectively. $c$ The accumulated installed power. The three curves represent the base case and the two scenarios discussed above

Since this is also cost effective, it is an important measure and stresses the significance of better quality means. The effect is of course even more important if good recycling measures are implemented. The combined effects of improving battery lifetime to 5 years and improving the recycling rate to $50 \%$ will lead to a much smaller environmental load of lead than that from the car industry.

$10^{6} \mathrm{~kW}$ Industrial production volume per year

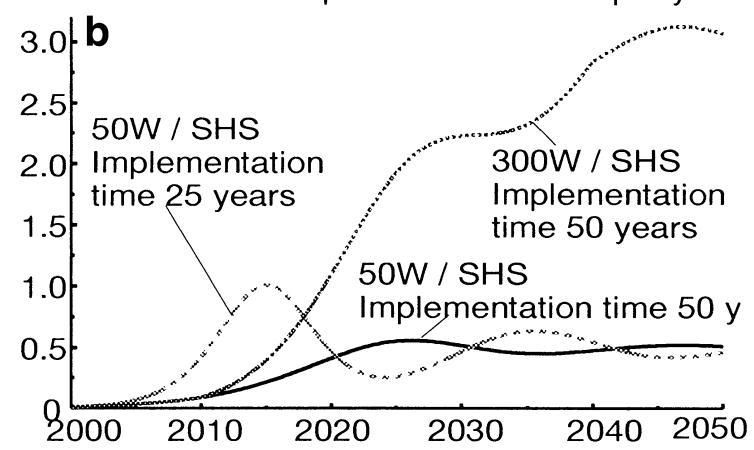

\section{Appendix: mathematical model for the "lead flux system"} Variables according to Fig. 2:

$M^{(1)}, \ldots, M^{(5)} \quad:$ leadstocks

$A_{12}, A_{23}, A_{32}, A_{24}, A_{42}, A_{35}, A_{45}:$ leadfluxes

Balance equations:

$$
\begin{aligned}
& \dot{M}^{(1)}=-A_{12} \\
& \dot{M}^{(2)}=A_{12}+A_{32}+A_{42}-A_{23}-A_{24} \\
& \dot{M}^{(3)}=A_{23}-A_{32}-A_{35} \\
& \dot{M}^{(4)}=A_{24}-A_{42}-A_{45} \\
& \dot{M}^{(5)}=A_{35}+A_{45}
\end{aligned}
$$

Model equations:

Assumed growth functions for the number of car and SHS batteries:

$M^{(3)}=P_{3}(t) \quad:$ lineargrowth

$M^{(4)}=P_{4}(t) \quad: \quad$ logisticgrowth

No average stock change in battery factories:

$\dot{M}^{(2)}=0$

Assumed residence time distributions for car and SHS batteries:

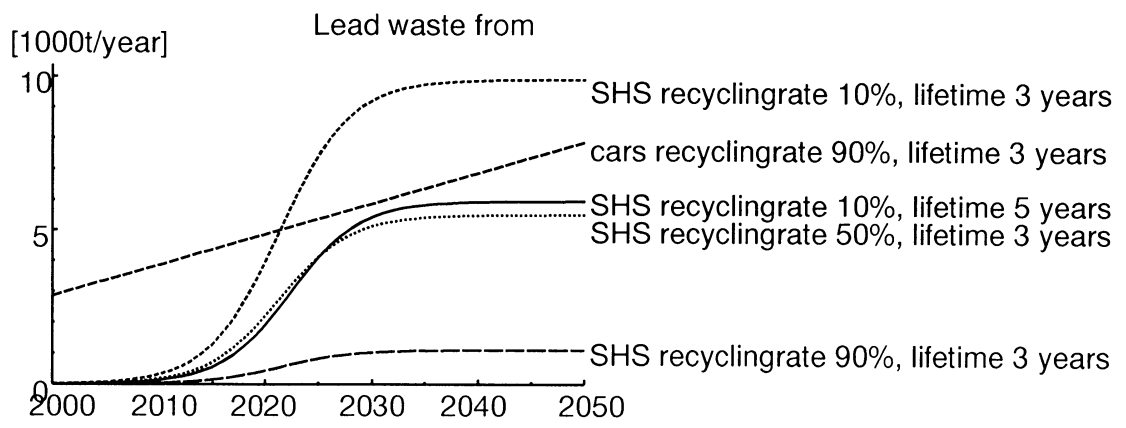

Fig. 5. Lead flux to the environment for the different cases of Table 2 
H.-P. Bader et al.: Large scale implementation of Solar Home Systems in remote, rural areas

Table 2. SHS parameters for the simulations

\begin{tabular}{lll}
\hline SHS & Recycling rate & Residence time \\
\hline Base case & $10 \%$ & 3 years \\
Improved residence time & $10 \%$ & $\begin{array}{c}\text { 3-5 years } \\
\text { (growing) }\end{array}$ \\
Improved recycling rate & $50 \%$ & 3 years \\
& $90 \%$ & 3 years \\
\hline
\end{tabular}

$A_{32}(t)+A_{35}(t)=\int_{0}^{t} k_{2}\left(t, t^{\prime}\right) A_{23}\left(t^{\prime}\right) \mathrm{d} t^{\prime}$

$A_{42}(t)+A_{45}(t)=\int_{0}^{t} k_{3}\left(t, t^{\prime}\right) A_{24}\left(t^{\prime}\right) \mathrm{d} t^{\prime}$

Known recycling rate for car and SHS batteries:

$$
\begin{aligned}
& A_{32}(t)=P_{5}(t)\left[A_{32}(t)+A_{35}(t)\right] \\
& A_{42}(t)=P_{6}(t)\left[A_{42}(t)+A_{45}(t)\right]
\end{aligned}
$$

The parameter function $P_{4}$ is similar to $P_{1}$ and $k_{2}$ and $k_{3}$ are similar to $k . P_{5}$ and $P_{6}$ are constant as a function of time, representing a constant recycling rate to a first approximation. For $P_{3}$ a linear growth has been assumed:

$$
P_{3}=p_{3,1}+p_{3,2}\left(t-p_{3,3}\right)
$$

\section{References}

Baccini P, Bader H-P (1996) Regionaler Stoffhaushalt. Spektrum Akad., Heidelberg

Binder C, Bader H-P, Scheidegger R, Baccini P (2001) Dynamic models for managing durables using a stratified approach: the case of Tunja, Columbia. Ecol Econ 38:191-207

EU2 European Commission of the European Communities (1996) Directorate-General for Energy: Photovoltaics in 2010. EPIAALTENER, Luxembourg

Global Green USA (2001) see www.globalgreen.org The solar venture fund: unleashing the power of the sun

Hug F (2002) Ressourcenhaushalt alpiner Regionen und deren physiologische Interaktion mit den Tiefländern im Kontext einer nachhaltigen Entwicklung. Dissertation 14540 ETH Zürich (http:// e-collection.ethbib.ethz.ch/cgi-bin/show.pl?type=diss\&nr=14540)

Lambert D (2001) Staying in charge\&mdash;batteries for small PV and solar home systems. Renewable Energy World 4/2. James \& James, London

Müller DB (1998) Modellierung, Simulation und Bewertung des regionalen Holzhaushaltes. Dissertation 12990 ETH Zürich (http://ecollection.ethbib.ethz.ch/cgi-bin/show.pl?type=diss\&nr=12937)

Real M (1998) A methodology for evaluating the metabolism in the large scale introductions of renewable energy systems. (http:// e-collection.ethbib.ethz.ch/cgi-bin/show.pl?type=diss\&nr=12937)

Zeltner C, Bader H-P, Scheidegger R, Baccini P (1999) Sustainable metal management exemplified by copper in the USA. Reg Environ Changes 1:31-46 